\title{
Michel Jeanneret, Versailles, ordre et chaos
}

\section{Laura Rescia}

\section{(2) OpenEdition}

\section{Journals}

\section{Edizione digitale}

URL: http://journals.openedition.org/studifrancesi/2141

DOI: 10.4000/studifrancesi.2141

ISSN: 2427-5856

\section{Editore}

Rosenberg \& Sellier

\section{Edizione cartacea}

Data di pubblicazione: 1 aprile 2014

Paginazione: 140-141

ISSN: 0039-2944

\section{Notizia bibliografica digitale}

Laura Rescia, « Michel Jeanneret, Versailles, ordre et chaos », Studi Francesi [Online], 172 (LVIII | I) | 2014, online dal 01 avril 2014, consultato il 18 septembre 2020. URL : http://journals.openedition.org/ studifrancesi/2141 ; DOI : https://doi.org/10.4000/studifrancesi.2141

\section{Questo documento è stato generato automaticamente il 18 settembre 2020.}

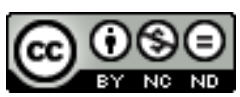

Studi Francesi è distribuita con Licenza Creative Commons Attribuzione - Non commerciale - Non opere derivate 4.0 Internazionale. 


\title{
Michel Jeanneret, Versailles, ordre et chaos
}

\author{
Laura Rescia
}

\section{NOTIZIA}

MICHEL JEANNERET, Versailles, ordre et chaos, Paris, Gallimard, 2012 («Bibliothèque illustrée des histoires»), pp. 376.

1 La pretesa unitarietà estetica del Grand Siècle è da tempo oggetto di revisione critica: è questa la direzione nella quale si inscrive anche l'importante studio di M. JEANNERET. Attraverso un percorso che comprende arti visive, teatrali, letterarie e musicali, l'A. intende dimostrare come le creazioni del periodo classico siano costantemente attraversate da una linea d'ombra, con l'affiorare di quella sottile angoscia sottesa alla percezione di una minaccia, indistinta ma imminente. Questo sentimento si concretizza con la fuga (o con la tentazione di fuga) verso il disordine, l'irregolarità, l'interruzione della linearità, in contrappunto costante con l'ordine, l'armonia, il rigore apparenti. Se una prima parte del testo è interamente dedicata all'estetica di Versailles, da cui il richiamo nel titolo, le successive si articolano sui diversi versanti artistici, ognuno corredato da ricche illustrazioni. L'itinerario prende dunque le mosse da una passeggiata nei giardini e tra le fontane del parco reale: l'evocazione della ben nota fonte letteraria di tale progetto, ovvero le Metamorfosi ovidiane, viene messa in relazione alla gran quantità di statue mostruose che rientrano nell'insieme, il quale «embrasse toute une frange d'êtres intermédiaires et mal différenciés, dont les anatomies composites défient le canon». Così nella fontana di Latona, i corpi umani parzialmente trasformati in batraci si tendono, distendendo le mani deformi in una smorfia dolorosa; e i dragoni, i satrapi, i giganti pietrosi emergono ad ogni passo intorno alle statue sorridenti e armoniose di Apollo e di Eros, così come le grotte e le grottesche, e i labirinti, che interrompono il rigore architettonico dei viali alberati. La rappresentazione della paura funziona, secondo l'A., come un talismano, un esorcismo, è un dramma complessivo inglobato nell'equilibrio e nell'armonia classica, 
intimamente, e quasi intrinsecamente, indissociabili dal loro contrario; come in un universo edenico pastorale, a tratti emerge, per parafrasare la ben nota definizione genettiana, «un serpent dans la bergerie». Il secondo itinerario, che prosegue con l'analisi degli spettacoli di corte (feste, comédie-ballets, balletti e opere liriche) relativi al ventennio 1660-1680, si rivela altrettanto produttivo. I fuochi illuminano la notte, emblema della luce del sovrano che domina il caos primitivo, ma evocano altresì $i$ campi di battaglia, i suoni del fronteggiarsi delle armate, la violenza che si innesta nella quietudine di una corte che, pur celebrando il dominio del caos ad opera dell'intelletto, si scopre fragile e rammenta la propria precarietà; lo spettacolo di esseri mostruosi e deformi evoca la presenza del Male, dell'orrore e dell'anarchia, presenti alla consapevolezza sociale e individuale. È questo il senso della presenza dell'animalità e della mostruosità nei moralisti come nei letterati del Grand Siècle: il bestiario che la classicità costruisce, attraverso La Fontaine, La Bruyère e Saint-Simon, rimette in gioco l'antropocentrismo affermando il disincanto di uno sguardo relativizzante sulle passioni e le virtù umane. Il sentimento dell'orrore in Racine e la presenza del male nei Contes di Perrault rispondono ad un identico bisogno: quello di reintegrare nell'equilibrio psichico la dimensione pulsionale. Positivo e negativo si appartengono: «il ne suffit pas de dire qu'une force évacue l'autre, elles s'appellent réciproquement».

2 Convincente, privo di eccessi di erudizione pur se opera di uno studioso che non necessita di conferme per la qualità e l'originalità dei suoi percorsi di ricerca, questo saggio appare particolarmente appassionante nelle prime due parti, dedicate all'architettura di Versailles e agli spettacoli di corte, mentre risultano meno innovative le parti relative alla letteratura. La piacevolezza della lettura è accresciuta dalle novantotto immagini che illustrano ed esemplificano il già cristallino tracciato intellettuale. 